\title{
Sulfasalazine Inhibits Inflammation and Fibrogenesis in Pancreas via NF- $\kappa B$ Signaling Pathway in Rats with Oxidative Stress-Induced Pancreatic Injury [Corrigendum]
}

Wang Y, Tian F, Yan M, et al. Drug Des Dev Ther. 2016;10:1743-1751.

The authors have advised Figure 1A on page 1746 is incorrect. The authors inadvertently chose $\mathrm{b}$ and $\mathrm{c}$ from the same group of candidate representative images dur- ing figure assembly. The correct Figure 1 is shown below.

The authors apologize for this error and advise it does not affect the results of the paper.
A
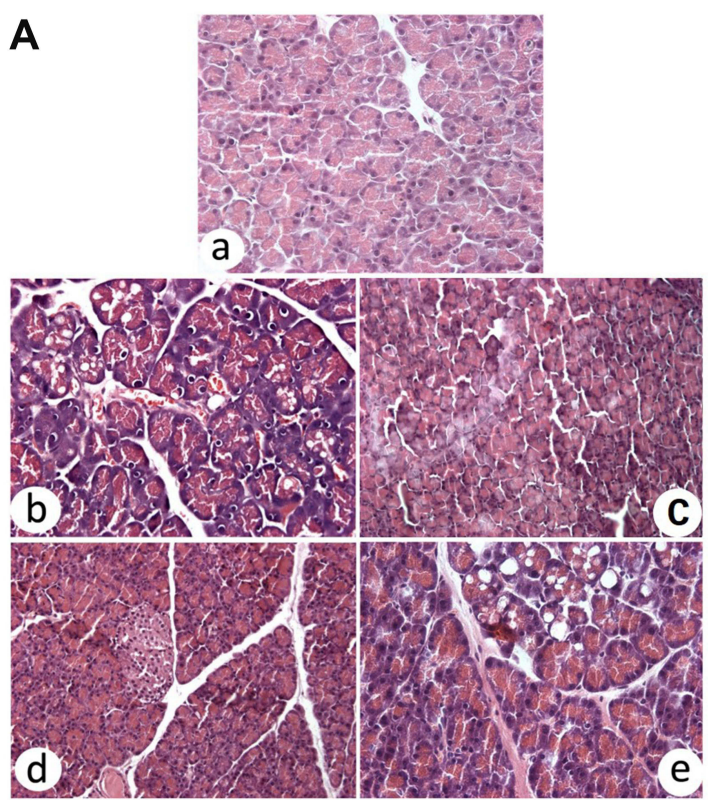

B

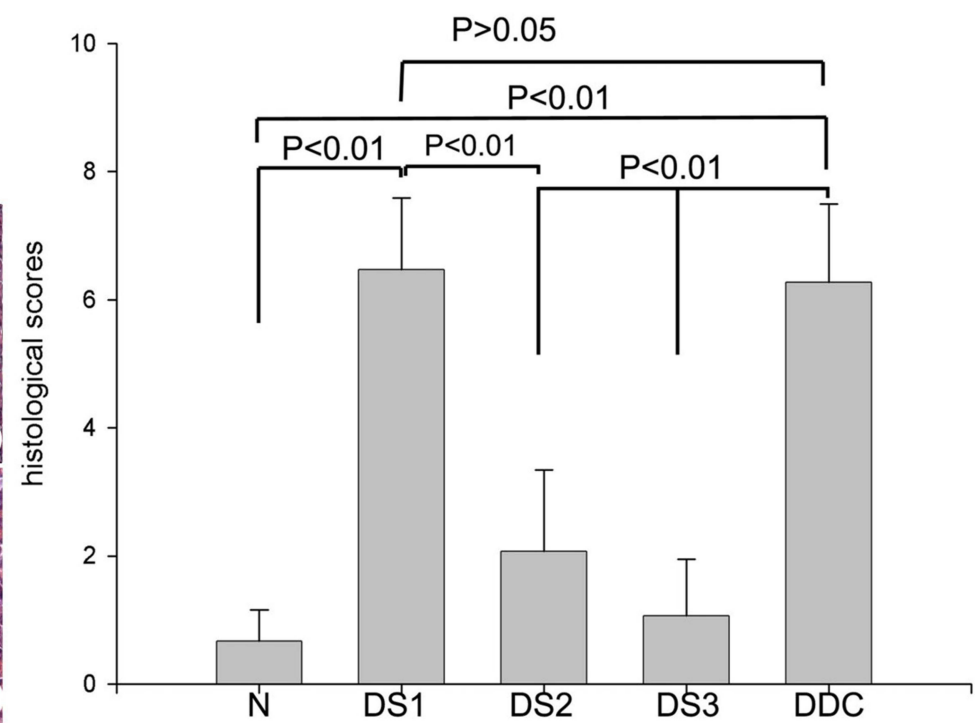

Figure I Pancreatic histological alterations (A) and histological scores (B).

Notes: (A, H\&E staining, original magnification 200x) Representative histological changes in pancreas in normal group (a), group DSI (b), DS2 (c), DS3 (d), and DDC (e). Quantitative analysis (B) demonstrates different pancreatic histological alterations in rats with different sulfasalazine (SF) treatments in different groups. Group N, normal control group, rats were treated with dilated water only; DSI, rats received SF ( $10 \mathrm{mg} / \mathrm{kg}$ ) 2 hours before DDC treatment; group DS2, rats were treated with DDC and then $\mathrm{SF}(100 \mathrm{mg} / \mathrm{kg}$, twice a week); group DS3, rats were treated with DDC, then SF (100 mg/kg, thrice a week); and group DDC, rats were treated with DDC only. Abbreviations: H\&E, hematoxylin and eosin; DDC, diethyldithiocarbamate.

\section{Publish your work in this journal}

Drug Design, Development and Therapy is an international, peerreviewed open-access journal that spans the spectrum of drug design and development through to clinical applications. Clinical outcomes, patient safety, and programs for the development and effective, safe, and sustained use of medicines are a feature of the journal, which has also been accepted for indexing on PubMed Central. The manuscript management system is completely online and includes a very quick and fair peer-review system, which is all easy to use. Visit http://www. dovepress.com/testimonials.php to read real quotes from published authors. 